\title{
PCBs contamination does not alter aerobic metabolism and tolerance to hypoxia of juvenile sole (Solea solea, L. 1758)
}

\author{
Cannas Marcella ${ }^{1}$, Atzori F. ${ }^{3}$, Rupsard F. ${ }^{4}$, Bustamante Paco ${ }^{1}$, Loizeau Veronique ${ }^{4}$, \\ Lefrançois Christelle ${ }^{1,{ }^{*}}$
}

1 Univ La Rochelle, CNRS, UMR 7266, Littoral Environm \& Soc LIENSs, F-17000 La Rochelle, France.

2 IFREMER, F-17137 Lhoumeau, France.

${ }^{3}$ Univ La Rochelle, IFREMER, CNRS, Federat Rech Environm Dev Durable FR EDD,FR 3097, F-17000

La Rochelle, France.

${ }^{4}$ IFREMER, Dept Dynam Environm Cotier, F-29280 Plouzane, France.

*Corresponding author : Christelle Lefrançois, email address : christel.lefrancois@univ-Ir.fr

\begin{abstract}
:
Coastal habitats play a major role as nurseries for many fish species; however, they are also submitted to pollutants and oxygen fluctuations. Fry's concept of metabolic scope for activity was used to evaluate the effect of polychlorinated biphenyls (PCBs) on the aerobic metabolism in juvenile common sole (0-1 year old). Aerobic metabolic scope (AMS) in control and PCB-contaminated fish via food pathway was determined using respirometry techniques. Furthermore, the hypoxia tolerance in control and PCBcontaminated fish was evaluated by assessing their critical oxygen concentration (O-2crit). Our results showed that while PCB-contaminated fish were able to maintain a constant AMS and O-2crit, PCBs tend to affect their aerobic metabolism by acting on maximal oxygen consumption (MO2max) in hypoxia and standard metabolic rate, but only at the highest PCB concentration between 30 and 60 days of exposure. In conclusion, we can hypothetise that the tested PCB-exposures may not impair the tolerance to hypoxia and the survival of common sole in their natural environment. (c) 2012 Elsevier B.V. All rights reserved.
\end{abstract}

\section{Highlights}

- Coastal habitats are often submitted to pollutants and oxygen fluctuations. We measured aerobic metabolic scope (AMS) in control and PCB-contaminated fish in both normoxic and hypoxic conditions, using respirometry techniques. We showed that $\mathrm{PCB}$-contaminated fish were able to maintain constant their AMS and critical oxygen saturation. We hypothesised that exposure to PCBs may not impair the tolerance to hypoxia and the survival of common sole in their natural environment.

Keywords : Bioenergetics, Aerobic metabolic scope, Persistent organic pollutant, Flatfish 


\section{Introduction}

Coastal areas play a key role as nurseries for juveniles of many species of teleosts. Such ecosystems are characterised by a high productivity and offer the food sources necessary for the development of growing juveniles (Gibson, 1994; Amara, 2001). However coastal areas are also under the influence of aquatic and terrestrial inputs, and are thereby particularly exposed to fluctuations in physico-chemical factors, such as salinity, temperature, oxygen, carbon dioxide and $\mathrm{pH}$. In addition, during the last decades, human activity brought about changes in water quality principally through the land-associated run-off and waste waters. These excessive inflows of nutrients (i.e. phosphorus and nitrogen) can induce eutrophication episodes often associated with hypoxia. Furthermore, land-associated waste water contains xenobiotics such as metals and persistent organic pollutants (POPs) leading to an increase of their concentrations in different compartments such as water and sediments.

Amongst the POP released in the marine environment, polychlorinated biphenyls (PCBs) are considered as the most toxic and widely distributed class (Abarnou, 2010). In invertebrates seawater constitutes an important exposure pathway (Danis et al., 2003, 2005 a,b) whereas vertebrates accumulate PCBs mainly by the trophic pathways (Boon, 1984; Kelly et al., 2007). Because of their high liposolubility, PCBs easily bioaccumulate in marine organisms and biomagnify along the food chain (Borga et al., 2001; Hoekstra et al., 2003; Nfon et al., 2008). Although their use as a raw material or chemical intermediate has been banned in the EC since 1985 (85/467/EEC, $6^{\text {th }}$ amendment to Directive 76/769/EEC), it is estimated that over $30 \%$ of the one million tons of PCBs produced are still present in aquatic and terrestrial ecosystems (Borlakoglu et al., 1991). PCBs provoke several toxicological responses, depending on the number and the position of their chlorine atoms (Ahlborg et al., 1994). For instance, previous studies showed that sub-lethal effects of PCB include: impairment of the 
neurosystem activity (e.g. in the Long-Evans rat, Rattus norvegicus, Lehmler et al., 2005); impairment of the endocrine system, as shown by the decrease in the level of cortisol circulating in response to stress (e.g. in yellow perch, Perca flavescens and northern pike, Exos lucius, Hontela et al., 1992; and in women, Mendola et al., 1997); decrease of the offspring number (e.g. in white-footed mice, Peromyscus leucopus, Voltura et al., 2007) and also impairment in swimming behaviour (e.g., in young carp, Cyprinus carpio, Schmidt et al., 2005). Nevertheless, only few studies to date have focused on the sub-lethal effects of PCBs on fish energetics (e.g. in European eel, Anguilla anguilla, van Ginneken et al., 2009) and on the interactions with other environmental stressors such as hypoxia (e.g. in killifish, Fundulus heteroclitus, Kramer and Schulte, 2004).

Bioenergetics studies give an essential viewpoint on the interactions between fish and their environment (Fry, 1971; Claireaux and Lefrançois, 2007). Fish activities (e.g., swimming, search for food, digestion, reproduction) are all related to energy-demanding processes that have to be accommodated within the animal aerobic metabolic scope (AMS). AMS was defined by Fry (1971) as the energy potential of an organism and is recognised as a proxy to assess physiological performance and fitness in fish (Priede, 1985; Claireaux et al., 2000; Mallekh and Lagardere, 2002; Claireaux and Lefrancois, 2007, Pörtner and Farrell, 2008; Guderley and Pörtner, 2010). AMS is partly driven by the environmental factors that were divided by Fry (1947, 1971) into five classes depending on their effects on aerobic metabolism: controlling, masking, limiting, lethal and directive factors. In this classification, oxygen and pollutants are considered as limiting factors as they interfere with metabolic processes and can thereby reduce the maximal metabolic rate sustainable by the organism, defined by Fry as the active metabolic rate (AMR). In addition, pollutants are classified as masking factors, since pollutant-related processes of defence and detoxification are likely to induce supplementary energy costs (Sokolova and Lannig, 2008, Niyogi et al., 2006). An 
associated elevation of the standard metabolic rate (SMR) measured in resting individuals (Fry, 1971) is therefore expected as observed in juvenile of rainbow trout (Oncorhynchus mykiss) exposed to sub-lethal concentrations of aluminium (Wilson et al., 1994).

In this context, the aim of our study was to investigate the effects of both sub-lethal concentrations of PCBs and hypoxia on the aerobic metabolism of common sole chronically exposed through the food pathway. Our main hypothesis was that chronic exposure to PCBs may constrain aerobic metabolic scope by reducing AMR and/or increasing SMR. Since a PCB-related increase in SMR would raise the oxygen requirement in resting fish, it can be hypothesised that such individuals may sooner experience respiratory distress when facing a progressive hypoxia. The influence of PCB contamination on the sole response to limited oxygen environment was therefore also investigated. This study focus on juvenile sole because 1) common sole is a bottom-dwelling species, which occupies the coastal zone during its juvenile phase; 2) during this phase, soles feed on the invertebrates living in the sediments which are expected to be highly contaminated by PCBs (Cicero, 2000; Chau, 2006) and 3) due to their reduced swimming capacity, soles have to cope with a set of interacting environmental stressors, such as hypoxia.

\section{Materials and methods}

\section{$\underline{2.1 \text { Experimental animals }}$}

Juveniles ( 1 year old) of common sole Solea solea (mean \pm S.D.; length: $11.4 \pm 1.0 \mathrm{~cm}$; mass: $16.0 \pm 3.6 \mathrm{~g}$ ) were obtained from a fish farm (Solea BV, Ijmuiden, Netherlands). Upon arrival at the laboratory, fish were transferred to 5001 indoor rearing tanks with recirculated and filtered seawater (temperature: $20^{\circ} \mathrm{C}$; salinity: $31 \mathrm{psu}$; fixed photoperiod: $12 \mathrm{~h} / 12 \mathrm{~h}$ ). Fish were then maintained for a three-week period of acclimation in the laboratory before being 
transferred in 601 glass-aquaria for the experiments. Soles were fed daily with commercial pellets. Feeding was discontinued $24 \mathrm{~h}$ before any manipulation of the fish.

\section{$\underline{2.2 \text { Protocol of food contamination }}$}

Sole contamination occurred through the food pathway. Food consisted of commercial pellets (DAN-EX 1362, Danafree ${ }^{\circledR}$ Horsens, Denmark) contaminated with a mixture of PCBs prepared by a specialised laboratory (IFREMER, Department of Biogeochemistry and Ecotoxicology, Brest, France) following the protocol described in Eichinger et al. (2010). Two concentrations of PCB were used; $[\mathrm{PCB}]_{\text {low }}$ and $[\mathrm{PCB}]_{\text {high }}$ which correspond to 670 and 2239 ng PCB $\mathrm{g}^{-1}$ of food, respectively. The lowest concentration was adjusted in order to experimentally attain a level of PCB contamination within in the range measured in juvenile

soles caught in the Seine estuary (i.e. an average hepatic concentration of $400 \mathrm{ng} \mathrm{PCB} \mathrm{g}{ }^{-1}$ dry weight, Loizeau, personal communication). This estuary is considered as the most heavily PCB contaminated area along the entire French coast (Abarnou and Simon, 1986). On the other hand, the highest concentration of $\mathrm{PCB}$ was $\sim 3.5$ times higher than $[\mathrm{PCB}]_{\text {low }}$ and was used as a positive control, which aimed at inducing PCB-related physiological effects. The PCB mixture employed for contamination contained four congeners selected because of their widespread presence in the environment: CB 105, CB 118, CB 149, and CB 153. The CB 153 $\left(2,2^{\prime}, 4,4^{\prime}, 5,5^{\prime}\right.$ - Hexachlorobiphenyl), a di-ortho-substituted compound, is one of the most abundant congener in marine organism. Albeit CB 153 has a low cytotoxicity, it is considered as the most recalcitrant congener with respect to the biotransformation and therefore the most persistent in the food web (Kannan et al., 1995). On the other hand, the CB 149 (2,2',3,4',5',6Hexachlorobiphenyl), a di-ortho-substituted compound, can be partially metabolised (Andersson and Förlin, 1992). The CB 105 (2,3,3',4,4'-Pentachlorobiphenyl) and CB 118 $\left(2,3^{\prime}, 4,4^{\prime} 5\right.$-Pentachlorobiphenyl) are mono-ortho-substituted which makes them more toxic 
than the other congeners. The congeners 118 and 153 are also considered amongst the 'indicator PCBs' as suggested by the International Committee for the Exploration of the Sea (ICES), i.e. these congeners are considered as a representative index of PCB contamination (MacGregor et al., 2010). For each congener, the concentration was measured in the experimentally-contaminated pellets (Table 1). Because of the low solubility of PCB, isooctane was used as solvent coating to facilitate their incorporation into the food. The concentration of the employed iso-octane was $40 \mathrm{ml} \mathrm{kg}^{-1}$ of pellets. After the incorporation of PCB, pellets were evaporated with a nitrogen jet in order to remove the solvent.

\subsection{Protocol of sole contamination}

Ten days before the beginning of contamination, 75 soles were anaesthetised with clove oil

$\left(0.04 \mathrm{ml} \mathrm{L}^{-1}\right)$, weighed, measured and then transferred into $60 \mathrm{~L}$ glass-aquaria. A total biomass of 100 g per aquaria (i.e. 6 to 9 fish) was maintained. All the aquaria were placed in a temperature controlled room where temperature was set to $20^{\circ} \mathrm{C}$ allowing constant thermal oscillations $<1{ }^{\circ} \mathrm{C}$ throughout the experiment. Ten days after their transfer into the aquaria, fish were exposed to one of the 4 following treatments: a group was fed with food containing the lowest concentration of $\mathrm{PCB}$ and a group with the highest one (i.e. group $P C B_{\text {low }}, \mathrm{n}=21$ and group $P C B_{h i g h}, \mathrm{n}=19$, respectively); a group was fed with food which contained the isooctane solvent (i.e. group Solvent, $\mathrm{n}=21$ ); and a group control was fed with uncontaminated food which contained no solvent (i.e. group Control, $\mathrm{n}=14$ ). Comparison between the group Solvent and the group Control was used to assess the effects of the solvent itself. Fish were daily fed with $1 \%$ of their total body mass. The food was given to the fish at once. After $\sim 6$ hours, the remaining pellets (i.e. not-eaten by the fish) were carefully removed. Fish were fed these diets up to 30 or 60 days. 


\subsection{Respirometry}

The experimental set up consisted of 4 respirometers $(4.5$ 1) placed into the same thermoregulated room as the aquaria. Inside of each respirometer, a flat propeller was set on a central axis and lay on the bottom in order to force the sole to swim when necessary. The axis was connected to a motor, whose speed was regulated by the experimenter between 0 and 67 turns $\min ^{-1}$. Respirometers were positioned in buffer tanks $(100 \mathrm{~cm} \times 80 \mathrm{~cm} \times 60 \mathrm{~cm})$, which aim at regulating the water temperature. Water supply in each respirometer was provided by flushing pumps placed in the buffer tanks. Each flushing pump was connected to a timer which regulated the flushing period. A pump was added to each respirometer to ensure an adequate mixing of the water inside of the measuring chamber. Oxygen content was measured with a polymer optical fiber (Presens, Germany) positioned on the wall of the respirometer and connected to a multichannel oxygen measuring system (OXY 4 mini, PreSens, Germany). Oxygen data were sampled every 30 seconds and recorded in a computer. Each buffer tank was equipped with a counter-current gas-equilibration column to control oxygen level. A pump supplied the column with the water coming from the buffer tank. An air stone positioned down in the water column bubbled air or nitrogen to set normoxia or hypoxia, respectively.

\subsection{Experimental protocol}

After 30 days of contamination, aerobic metabolism was assessed by intermittent flow-

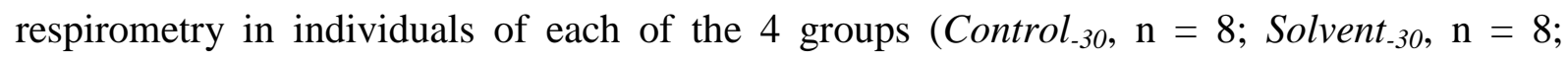
$P C B_{\text {low-30 }}, \mathrm{n}=7$ and $P C B_{\text {high-30 }}, \mathrm{n}=8$ ). The other soles were maintained in the aquaria for a longer contamination lasting 60 days and constituted the groups Control $_{-60}(\mathrm{n}=6)$, Solvent -60 ( $\mathrm{n}=13), P C B_{\text {low-60 }}(\mathrm{n}=14)$ and $P C B_{\text {high-60 }}(\mathrm{n}=11)$. Fish were tested once and individually. An experiment lasted 3 days, during which one fish of each treatment (i.e. a total of 4 fish) 
were concomitantly tested in the 4 respirometers. An experiment consisted in exposing each fish to 3 consecutive steps. First, as soon as transferred into the respirometer, each fish was chased in order to increase its energy-demanding activities and assess active metabolic rate (AMR), defined as the fish maximal metabolic rate in normoxia, i.e. in non-limiting oxygen conditions (Fry 1971). To force fish to swim, the propeller connected to the motor was switched on until the fish reached exhaustion (i.e. when the fish was not able to swim anymore, which occurred within $\sim 10 \mathrm{~min})$. Then, fish oxygen consumption $\left(\mathrm{MO}_{2}\right)$ was measured during $30 \mathrm{~min}$. The second step consisted in exposing sole to a progressive hypoxia in order to assess (i) the maximal $\mathrm{MO}_{2}\left(\mathrm{MO}_{2 \max }\right)$ the fish can sustain as a function of limited oxygen levels, as well as (ii) the critical oxygen saturation $\left(\mathrm{O}_{2 \text { crit }}\right)$. Fish were therefore successively exposed to four level of water oxygenation: $60 \%, 40 \%, 20 \%$ and $10 \%$. At each of these levels, fish were chased until exhaustion by activation of the propeller in order to raise its $\mathrm{MO}_{2}$ to the maximum allowed by the oxygen level tested. After the last measurement, normoxia was restored (within $\sim 15 \mathrm{~min}$ ) by bubbling oxygen into the counter-current gasequilibration column. Thirdly, $\mathrm{MO}_{2}$ was measured in resting animals to estimate standard metabolic rate (SMR). To do so, the propeller was switched off and fish were left undisturbed throughout the following $48 \mathrm{~h}$ during which measurements of $\mathrm{MO}_{2}$ carried out automatically. Each measure of $\mathrm{MO}_{2}$ lasted 30 minutes and a flushing period of 25 minutes was respected between consecutive measurements. Blank respiration was routinely assessed before and after each experiment by assessing $\mathrm{MO}_{2}$ in empty respirometers to be afterwards subtracted to the total measure of $\mathrm{MO}_{2}$.

\section{$\underline{2.6 \text { Calculation of the oxygen consumption and } \mathrm{O}_{2} \text { crit }}$}

The fish $\mathrm{MO}_{2}\left(\mathrm{mgO}_{2} \mathrm{~kg}^{-1} \mathrm{~h}^{-1}\right)$ was calculated with the following equation, commonly employed in such studies (Lefrançois and Claireaux, 2003): 


$$
M O_{2}=\Delta\left[\mathrm{O}_{2}\right] \cdot \Delta t^{-1} \cdot V O L_{\text {resp }} \cdot m^{-1}
$$

where $\Delta\left[\mathrm{O}_{2}\right]$ is the decrease in water oxygen concentration $\left(\mathrm{mgO}_{2} \mathrm{l}^{-1}\right)$ during the measuring period $(\Delta t), V O L_{\text {resp }}$ is the volume of the respirometer (4.5 l) minus the volume of the fish and $m$ is the mass of the fish. To determine $\Delta\left[\mathrm{O}_{2}\right] . \Delta t^{-1},\left[\mathrm{O}_{2}\right]$ was plotted as a function of time and a linear regression was adjusted for each $\mathrm{MO}_{2}$ measurement ( $\mathrm{R}$ development Core Team 2011, version 2.13.2, script D. Chabot (C)). The regression coefficient $\left(\mathrm{R}^{2}\right)$, which illustrates the accuracy of the regression, was $>0.98$ in all cases.

Since the respiratory metabolism depends on the animal mass, each $\mathrm{MO}_{2}$ was then standardised for a $0.1 \mathrm{~kg}$ fish using the following relationship (Lefrançois and Claireaux, 2003):

$\mathrm{MO}_{2 \text { cor }}=\mathrm{MO}_{2} \cdot\left(\mathrm{m} \cdot \mathrm{m}_{\mathrm{cor}}^{-1}\right)^{1-\mathrm{A}}$

where $\mathrm{MO}_{2}$ cor $\left(\mathrm{mgO}_{2} \mathrm{~kg}^{-1} \mathrm{~h}^{-1}\right)$ is the oxygen consumption of a fish with a corrected mass (i.e., $\mathrm{m}_{\text {cor }}=0.1 \mathrm{~kg}$ in the present case $), \mathrm{MO}_{2}\left(\mathrm{mgO}_{2} \mathrm{~kg}^{-1} \mathrm{~h}^{-1}\right)$ is the measured oxygen consumption calculated with Eq. (1) and $\mathrm{m}(\mathrm{kg})$ is the mass of the fish experimentally tested. The coefficient $\mathrm{A}$ is the allometric exponent describing the relationship between the metabolic rate and the body mass. A value of 0.8 was used as in other teleosts (Steffensen et al., 1994).

\subsection{Assessment of Active Metabolic Rate (AMR), Standard Metabolic Rate (SMR), Aerobic}

\section{Metabolic Scope (AMS) and critical oxygen saturation $\left(\mathrm{O}_{2}\right.$ crit $\mathrm{\perp}$}

AMR was assessed as the $\mathrm{MO}_{2}$ measured in exhausted fish after being chased. In order to assess SMR, a frequency distribution of the $\mathrm{MO}_{2}$ values measured during the last 48 hours 
was plotted, as recommended by Steffensen et al. (1994). In general, it is possible to observe a bimodal frequency distribution, due to the fact that fish may present routine activity. The first peak is considered to reflect the value of the SMR, and the second is considered to be the consequence of the routine activity (Steffensen et al., 1994). Since we did not notice such a difference in the frequency distribution of $\mathrm{MO}_{2}$, only the data measured during the last day were used. During this period, the fish was supposed to recover from the stress derived from experimental manipulation and from hypoxia exposure (Steffensen et al., 1994). AMS was calculated as the difference between AMR and SMR.

$\mathrm{MO}_{2 \max }$, and as consequence AMS, decrease with water oxygen content (van den Thillart et al., 1994; Claireaux and Lagardère, 1999; Lefrançois and Claireaux, 2003; Dutil et al., 2007; Chabot and Claireaux, 2008). Critical oxygen saturation $\left(\mathrm{O}_{2 \text { crit }}\right)$ was defined as the water oxygen content at which the maximal sustainable $\mathrm{MO}_{2 \max }$ was equal to $\mathrm{SMR}$, i.e. when the AMS was null (Fry, 1948; Steffensen et al., 1994; van den Thillart et al. 1994; Schurmann and Steffensen, 1997; Iversen and McKenzie, 2010). $\mathrm{O}_{2 \text { crit }}$ was evaluated according to the method proposed by Bilberg et al. (2010). Briefly, $\mathrm{MO}_{2 \max }$ was plotted as a function of oxygen water saturation. Hereafter, a curve was fitted using the 'exponential rise to maximum' function $\left[y=a\left(1-\exp ^{-b x}\right)\right.$ ] (SigmaPlot, Systat Software 11.0). For each fish, $\mathrm{O}_{2 \text { crit }}$ was defined as the intersection between the curve obtained, and its SMR and according to the following equation:

$$
\mathrm{O}_{2 \text { crit }}=\left(\frac{-\ln (1-(\mathrm{SMR} / \mathrm{a})}{\mathrm{b}}\right)
$$

where $a$ and $b$ are the constants provided by the curve fittings software.

AMR, SMR, AMS, as well as $\mathrm{O}_{2 \text { crit }}$ were assessed in each fish. 


\section{$\underline{2.8 P C B \text { analysis }}$}

After the dietary exposure period, soles were killed by an overdose of anesthetic (Clove oil: $0.2 \mathrm{ml} \mathrm{L}^{-1}$ ), the liver was removed and frozen at $-80{ }^{\circ} \mathrm{C}$ for further analysis of PCB contents. Concentration of CB 153, CB 118, CB 149 and CB 105 were measured in the liver according to the protocol described in Jaouen-Madoulet et al. (2000). Only the data concerning the CB 153 are presented (Table 2) as an indicator of the level of contamination of the sole, since (i) CB153 is poorly metabolised in comparison to the three other congeners and (ii) it has been shown to have a good correlation with the sum of congeners present in the sample (Atuma et al. 1996). Briefly, frozen livers were freeze-dried and then ground to obtain a fine homogeneous powder. Water content was estimated by the determination of the weight lost after freeze-drying. To quantify the PCBs contained in the powdered materials, a weighed amount was solvent-extracted (by a hexane: acetone mixture 80:20, respectively using a hot Soxhlet extraction apparatus (Soxtec). Subsequently, the solvent was completely evaporated using a rotavapor. In order to purify PCB-containing fractions, the extracts were cleaned-up by addition of concentrated sulphuric acid to destroy lipids and co-extractible materials (Jaouen-Madoulet et al. 2000). PCBs were then quantified by gas chromatography, with an electron capture detector on a HP 5890 series II equipped with a CP-Sil19 capillary column following optimised conditions as described in details by Jaouen-Madoulet et al. (2000) and Bilberg et al. (2008). Contamination by the congener CB 153 was quantified using a standard solution. Hepatic concentration of CB 153 (ng g ${ }^{-1}$ of dry weight, hereafter d.w.) was measured after 30 and 60 days of contamination (i.e. $\mathrm{n}=6$ and $\mathrm{n}=7$ for $P C B_{\text {low }}$ and $\mathrm{n}=7$ and $\mathrm{n}=7$ for $P C B_{\text {high }}$ at 30 and 60 days, respectively). Limit of detection of CB 153 was $1.2 \mu \mathrm{g}^{-1}$.

\subsection{Statistical analysis}


AMR, SMR, AMS and $\mathrm{O}_{2 \text { crit }}$ measures were examined for normality and homogeneity of variance. Two-way ANOVA was used to determine the effect of PCB exposure on the variables $\mathrm{AMR}, \mathrm{SMR}, \mathrm{AMS}$ and $\mathrm{O}_{2 \text { crit. }}$ ANOVAs were set with the different treatments (i.e. $P C B_{\text {low }}, P C B_{\text {high, }}$ and Solvent vs. Control) and both contamination periods (i.e. 30 vs. 60 days) as main factors. Two-way ANOVA with treatments $\left(P C B_{\text {low }}, P C B_{\text {high }}\right)$ and contamination periods (30 and 60 days) as main factors was used to compare the hepatic concentration of CB 153 between the fish from the groups $P C B_{\text {low }}$ and $P C B_{\text {high }}$. In addition, a Pearson test was employed to evaluate the correlation between the hepatic concentration of $\mathrm{CB} 153$ of the PCB-contaminated groups and the variables AMR, SMR and $\mathrm{O}_{2 \text { crit. }}$ Because it has been already showed that in sole $\mathrm{MO}_{2 \max }$ declines as oxygen availability decreases (van den Thillart et al., 1994; Claireaux and Lagardère, 1999; Lefrançois and Claireaux, 2003; Dutil et al., 2007; Chabot and Claireaux, 2008), statistical analysis were focused on the effects of PCB on $\mathrm{MO}_{2 \max }$ To do that, at each levels of water air saturation (i.e. at $100 \%, 60 \%, 40 \%, 20 \%$ and $10 \%$ in air saturation, hereafter a.s.) a two-way ANOVA was employed with contamination periods (30 versus 60 days) and treatment (Solvent, $P C B_{\text {low }}, P C B_{\text {high }}$ vs. Control) as main factors. When ANOVA revealed a significant effect, Tukey's post hoc test was employed to assess the statistical significance of specific differences in the statistical analysis design, and a planned comparison was used to compare the treatment Control to each of the three others treatments when a significant interaction between the factors tested was found, (Underwood, 1981). The level of statistical significance was set to $\mathrm{P}<0.05$. Statistical analyses were conducted using STATISTICA 8.0 (StatSoft, Inc., USA). Data are presented as mean \pm S.D.

\section{Results}


Hepatic CB 153 concentrations in individuals from the groups Control and Solvent were negligible, i.e. 36 and $29 \mathrm{ng} \mathrm{PCB} \mathrm{g} \mathrm{g}^{-1}$ of food respectively, contrary to the concentrations measured in the contaminated soles (Table 2). CB 153 concentrations showed a significant effect of the treatments $\left(\mathrm{F}_{1: 24}=13, \mathrm{P}<0.01\right)$ which differed with the exposure period to the pollutant $\left(\mathrm{F}_{1: 24}=7.6, \mathrm{P}<0.05\right.$ for the interaction term $)$. Planned comparison showed that $\mathrm{CB}$ 153 concentration between the groups $P C B_{l o w-30}$ and $P C B_{h i g h-30}$ was not significantly different (P > 0.05). On the contrary in individuals contaminated during 60 days, CB 153 concentration was approximately two-fold higher in soles belonging to the group $P C B_{\text {high-60 }}$ than those of the group $P C B_{\text {low-60 }}(\mathrm{P}<0.05)$. Independent of the exposure period and PCB treatments, no significant correlation was observed between the hepatic CB 153 concentration and AMR $\left(0.02<\mathrm{r}^{2}<0.16, \mathrm{P}>0.05\right.$ in all cases $)$ as well as for the hepatic CB 153 concentration and $\mathrm{O}_{2 \text { crit }}\left(0.14<\mathrm{r}^{2}<0.49\right.$ and $\mathrm{P}>0.05$ in all cases $)$. For SMR, a similar pattern was observed for the individuals belonging to the groups $P C B_{\text {low }-30}$ and $P C B_{\text {high }-30}$ and for $P C B_{\text {low }-60}\left(0.03<\mathrm{r}^{2}<\right.$ 0.6 and $\mathrm{P}>0.05$ in all cases), except for the individuals exposed to $P C B_{\text {high-60 }}$, for which a positive correlation was found $\left(\mathrm{r}_{\mathrm{PEARSON}}=0.85 ; \mathrm{P}<0.001\right.$, Fig. 1$)$.

No significant effect of treatments was found on SMR, AMR, AMS and $\mathrm{O}_{2 \text { crit }}$, (treatment $\mathrm{P}$ > 0.05 in all cases; Table 3). The exposure period had a significant effect exclusively on $\mathrm{O}_{2 \text { crit }}$ $\left(\mathrm{F}_{1: 41}=5.4, \mathrm{P}<0.05\right)$. A significant interaction between the two factors tested (exposure period and treatment) was observed only on $\operatorname{SMR}\left(\mathrm{F}_{3: 67}=2.8, \mathrm{P}<0.05\right)$. A posteriori planned comparison showed that this pattern was due to the soles exposed to the highest PCB concentration, which showed a SMR significantly higher after 60 days of contamination than after 30 days $(\mathrm{P}<0.05)$. 
Regardless of the treatment and the exposure period to PCBs, a general decrease in $\mathrm{MO}_{2 \max }$ with hypoxia was observed (Fig. 2). In severe hypoxia (<20\% a.s.), $\mathrm{MO}_{2 \max }$ did not show any significant difference among the four treatments $(\mathrm{P}>0.05)$ neither between the 30 and 60 days of exposure $(\mathrm{P}>0.05$, for both exposure period and interaction term in all cases). Only few isolated significant differences were observed at $60 \%$ and $40 \%$ a.s. (Fig 2). At $60 \%$ a.s., a significant effect of both treatments $\left(\mathrm{F}_{3: 67}=3.9, \mathrm{P}<0.05\right)$ and duration of contamination $\left(\mathrm{F}_{1: 67}\right.$ $=6.2, \mathrm{P}<0.05)$ was found $($ Fig.2), while no interaction was detected $(\mathrm{P}>0.05)$. Tukey's post-hoc test revealed a significant difference between the Solvent and the $P C B_{\text {low }}$ treatments. At $40 \%$ a.s., only a significant effect of duration of contamination was found $\left(\mathrm{F}_{1: 67}=9.1, \mathrm{P}<\right.$ 0.01; Fig.2).

\section{Discussion}

The results suggested that under our experimental conditions, PCB exposure did not affect AMR, AMS or $\mathrm{O}_{2 \text { crit. }}$ The unique variable influenced was the SMR, but only at the highest PCB concentration between 30 and 60 days of exposure.

In the current study, the average AMR measured in sole ranged between $129.5 \pm 22.2$ and $173.2 \pm 73.9 \mathrm{mgO}_{2} \mathrm{~kg}^{-1} \mathrm{~h}^{-1}$. These data are in agreement with previous studies carried out on the same species at $20{ }^{\circ} \mathrm{C}$ [i.e. $152.2 \mathrm{mgO}_{2} \mathrm{~kg}^{-1} \mathrm{~h}^{-1}$ in van den Thillart et al. (1994) and 159.2 $\mathrm{mgO}_{2} \mathrm{~kg}^{-1} \mathrm{~h}^{-1}$ in Lefrançois and Claireaux (2003)]. Neither AMR nor AMS were influenced by the PCB contamination experimentally-induced in the present study (Tables 2 and 3). This suggests that the sub-lethal concentrations of PCB we tested did not prevent the soles from meeting their maximal oxygen requirements. Therefore PCB-exposed soles should not present any reduction in oxygen-demanding activities such as locomotion, digestion or growth (Claireaux and Lefrançois, 2007). The growth rate was not assessed in this study. However, 
our results are consistent with a recent study carried out on juvenile of common soles exposed to the same protocol of contamination, and which showed that PCB-exposure did not affect growth (Eichinger et al.; 2010). In addition, the PCB-treatments did not influence the maximal metabolic rate the sole can sustain $\left(\mathrm{MO}_{2 \max }\right)$ in hypoxic conditions. Indeed, contaminated sole never showed significant difference in $\mathrm{MO}_{2 \max }$ when compared to Control individuals (Figure 2); while $\mathrm{MO}_{2 \max }$ strongly declined with the oxygen as observed in the same species by Lefrançois and Claireaux (2003), as well as in other fish species by various authors (Priede, 1985; Schurmann and Steffensen, 1997; Chabot and Claireaux, 2008; Iversen and McKenzie, 2010). This suggests that PCB contamination does not impair the organs and cellular mechanisms involved in the oxygen transport contrary to other type of pollutants. For instance, tributyltin chloride contained in the antifouling paints for boats, was found to affect red cell function in rainbow trout (Oncorhynchus mykiss, Virkki and Nikinmaa, 1993). Oiltreated soles exposed to normoxic and hypoxic conditions showed reduced $\mathrm{MO}_{2 \max }$ associated to weakened cardiovascular performance (Davoodi and Claireaux, 2007; Claireaux and Davoodi, 2010). PCBs and hypoxia response induce both the activation of Ah-receptor, by using the same transcriptional pathways. As a consequence, PCB-hypoxia interaction may be hypothesised, which could affect the findings (Nie et al. 2001; Nguyen and Bradfield, 2008; Fleming et al. 2009). The lack of information regarding the specific effects of PCBs on such functions limits further discussion. Moreover, it cannot be excluded that the solvent employed to fix PCB on the experimental-contaminated pellets (i.e. iso-octane) participated to the regulation in $\mathrm{MO}_{2 \max }$ of soles while coping with mild hypoxia (Fig 2).

Energy balance in an organism also depends on the part of energy obligatorily allocated to its maintenance activities. SMR measured in the uncontaminated soles (Table 3) are in agreement with the SMR assessed in $20^{\circ} \mathrm{C}$-acclimated sole by van den Thillart et al. (1994; $\left.41 \mathrm{mgO}_{2} \mathrm{~kg}^{-1} \mathrm{~h}^{-1}\right)$ and Lefrançois and Claireaux (2003; $\left.49 \mathrm{mgO}_{2} \mathrm{~kg}^{-1} \mathrm{~h}^{-1}\right)$. SMR only differed 
between the soles exposed to the highest concentration of PCB during 30 and 60 days (i.e. $P C B_{\text {high-30 }}$ versus $P C B_{\text {high-60; }}$; Table 3). In the particular $P C B_{\text {high-60 }}$ treatment, SMR tends to increase with CB 153 concentration, even if the type of relationships cannot be established (Fig. 1). Data do not allow assessing if SMR may increase proportionally with PCB or only above a determined threshold. Nevertheless, the most relevant observation is that no significant difference was detected between the Control and the contaminated sole. This suggests that maintenance activities do not tend to be significantly influenced by the PCB contamination experimentally-induced in the present study. This is contrary to our initial hypothesis, which stated that an increase in SMR was expected because of supplementary energy costs induced by PCB-related processes of defence and detoxification. For instance, Lannig et al., (2006) showed a 40-86\% increase of SMR in cadmium-exposed oyster, Crassostrea virginica. They concluded that this pattern was mostly due to the elevated costs of protein synthesis involved in detoxification or protective mechanism such as glutathione expression, antioxidant enzyme, cellular repair mechanism, as well as expression of stress proteins.

Critical oxygen saturation is defined as the minimal level in water oxygen content needed to sustain SMR (Fry, 1948; Steffensen et al., 1994; van den Thillart et al. 1994; Schurmann and Steffensen, 1997; Iversen and McKenzie, 2010). Facing a progressive hypoxia, individuals with an elevated $\mathrm{O}_{2 \text { crit }}$ would sooner be unable to extract enough oxygen to meet their SMR, and have thus to cope with physiological distress. Absence of difference in $\mathrm{O}_{2 \text { crit }}$ in healthy soles when compared to those contaminated to PCB is consistent with the absence of PCB effects observed for SMR. It can thus be hypothesised that the PCB concentrations tested would not affect the tolerance to hypoxia in soles by influencing their aerobic metabolism. However, it is worth noting that in the killifish Fundulus heteroclitus exposed to hypoxia, glycolytic enzymes were down-regulated in presence of PCB, which thereby limits the 
efficiency of the anaerobic pathway (Kraemer and Schulte, 2004). Compensation of the hypoxia-related reduced supply in ATP, as well as maintenance of the energy-demanding activities, may be therefore limited by PCB.

Even if a large range of PCB concentration was tested in the present study (i.e. the highest concentration tested was four-fold higher than the levels measured in wild juvenile soles from the Bay of Seine, Loizeau, personal communication), no clear pattern was revealed. Furthermore, comparisons with other studies suffer from a lack of available data, mainly because of differences in the type of pollutants tested and/or in the experimental approach employed for contamination. For instance, effect of PCB was investigated in the European eel (Anguilla anguilla) by van Ginneken et al. (2009) who showed that PCB-contaminated eels were characterised by lower aerobic metabolism than healthy individuals. However, adult eels were injected intraperitoneally with a mixture of PCB consisting of $\mathrm{CB} 153,126$ and 77 at very high concentrations (i.e. $5 \mathrm{mg} \mathrm{kg}^{-1}, 7 \mu \mathrm{g} \mathrm{kg}^{-1}$ and $50 \mu \mathrm{g} \mathrm{kg}^{-1}$ of body weight, respectively). Furthermore, aerobic metabolism was measured in individuals swimming at a low speed (i.e. 0.5 body length $\mathrm{s}^{-1}$ or $0.4 \mathrm{~m} . \mathrm{s}^{-1}$ ) and was therefore representative of the eel routine metabolic rate rather than the maximal, or active, level. Another study (Voltura et al., 2007) carried out on the white-footed mouse (Peromyscus leucopus) showed no effect of PCB on energy metabolism and growth. The authors suggested that this finding may be due to a large dosedependent decrease in thyroid hormone concentrations. To date, it appears that comparative assessment of the effects of PCB exposure on aerobic metabolism is limited and that scattered information prevents a general pattern from emerging. Effects of metal pollution were on the contrary extensively studied (e.g. Sibly and Calow, 1989; Calow and Forbes, 1998; Sherwood et al., 2000). However, despite these numerous studies, effects of metals on aerobic metabolism are still controversial (see the review by Sokolova and Lannig, 2008). Effects appear to be dependent of a large set of factors such as the metal studied, its concentration, the 
pathway of metal uptake, as well as other natural factors such as temperature. It is likely that the effects of PCB and those of POP in general follow the same pattern.

\section{Acknowledgments}

This research was supported by the Autonomous Sardinia Region through a PhD grant for M. Cannas. This study also benefited financial support of the ANR funded SoleBeMol project (project no.: ANR-06-PVULN-O13-IFREMER No.07/2.210/F) and from the Contrat de Projet Etat-Région (CPER) "Littoral et Environnement". The authors are indebted to D. Chabot to have provided the program $\mathrm{R}$ (development Core Team 2011, version 2.13.2) necessary to analyse the metabolism data and to M. Prineau (FR 3097 CNRS-IFREMERUniversity of La Rochelle) for its technical contribution. We are grateful to the IFREMER, Institut Français pour la Recherche et l'Exploitation de la Mer, Houmeau, and particularly to V. Loizeau who chaired the SoleBeMol project, ML Begout for the facilities and for the biological material furnished. All experimental procedures in this work comply with the current laws in France.

\section{References}

Abarnou, A., Simon, S., 1986. Contamination de l'estuaire et de la baie de Seine par les PCBs. In La baie de Seine, Groupe de recherches coordonnées Manche (Greco Manche), Actes de colloques No. 4, pp. 471-476. Ifremer, Université de Caen.

Abarnou, A., 2010. Utilisation d'espèces halieutiques exploitées comme indicateurs de la contamination chimique en zone littorale. http://archimer.ifremer.fr/doc/00014/12475/

Ahlborg, U.G., Becking, G.C., Birnbaum, L.S, Brouwer, A., Derks, H.J.G.M., Feeley, M., Color, G., Hanberg, A., Larsen, J.C., Liem, A.K.D., Safe, S.H., Schlatter, C., Wvern, F., Younes, 
M., Yrjäinheikki, E., 1994. Toxic equivalency factors for dioxine-like PCBs. Chemosphere. 28 (6), 1049-1067.

Amara, R., Laffargue, P., Dewarumez, J.M, Maryniak, C., Lagardère, F., Luczac, C. 2001. Feeding ecology and growth of O-group flatfish (sole, dab and plaice) on a nursery ground (Southern Bight of the North Sea). J. Fish Biol. 58, 788-803.

Andersson, T., Förlin, L., 1992. Regulation of the cytochrome P450 enzyme system in fish. Aquat. Toxicol. 24, 1-20.

Atuma, S.S., Linder , C.E., Andersson, O., Bergh, A., Hansson, L., Wicklund-Glynn, A. (1996). CB153 as indicator for congener specific determination of PCBs in diverse fish species from Swedish waters. Chemosphere 33 (8), 1459-1464.

Bilberg, K., Malteb, H., Wang, T., Baatrup, E., 2010. Silver nanoparticles and silver nitrate cause respiratory stress in Eurasian perch (Perca fluviatilis). Aquat. Toxicol. 96, 159165.

Bodiguel X., Tronczyński J., Loizeau V., Munschy C., Guiot N., Le Guellec A.M., Olivier N., Roupsard F., Mellon C., 2008. Classical and novel organohalogen compounds (PCBs and PBDEs) in hake (M. merluccius, L.) from Mediterranean and Atlantic coasts (France). WIT Trans. Ecol. Environ 110, 157-166.

Boon, J.P., Oudejans, R.C.H.M, Duinker, J.C., 1984. Kinetics of individual polychlorinated biphenyl (PCB) components in juvenile sole (Solea solea) in relation to their concentrations in food and to lipid metabolism. Comp. Biochem. Physiol. C: 79(11), 131-142.

Borlakoglu, J.T., Haegele, K.D. 1991. Comparative aspects on the bioaccumulation, metabolism and toxicity with PCBs. Comp. Biochem. Physiol. C, 100(3), 327-338.

Calow, P., Forbes, V.E., 1998. How do physiological responses to stress translate into ecological and evolutionary processes? Comp. Biochem. Physiol. A120, 11-16. 
Chabot, D., Claireaux, G., 2008. Environmental hypoxia as a metabolic constraint on fish: The case of Atlantic cod, Gadus morhua. Mar. Pollut. Bull. 57, 287-294.

Chau, K.W., 2006. Persistent organic pollution characterization of sediments in Pearl River estuary. Chemosphere 64(9), 1545-1549.

Cicero, M., Finoia, MG., Gabellini, M., Veschetti, E., 2000. Concentration and distribution of persistent organic pollutants (POPs) in harbor dredging sediments: a pilot study using a statistical approach for a more efficient characterization and management. Environ. Monit. Assess. 64, 607-616.

Claireaux, G., Lagardère, J.-P., 1999. Influence of temperature, oxygen and salinity on the metabolism of European sea bass. J. Sea Res. 42, 157- 168.

Claireaux, G., Webber, D. M., Lagardère, J.-P., Kerr, S. R., 2000. Influence of water temperature and oxygenation on the aerobic metabolic scope of Atlantic cod (Gadus morhua). J. Sea Res. 44, 257-265.

Claireaux, G., Lefrançois, C., 2007. Linking environmental variability and fish performance: integration through the concept of scope for activity. Phil. Trans. R. Soc. B 362, 20312041.

Claireaux, G., Davoodi, F., 2010. Effect of exposure to petroleum hydrocarbons upon cardiorespiratory function in the common sole (Solea solea). Aquat. Toxicol. 98, 113-119.

Davoodi F., Claireaux G., 2007. Effects of exposure to petroleum hydrocarbons upon the metabolism of the common sole Solea solea. Mar. Pollut. Bull. 54, 928-934.

Danis, B., Cotret, O., Teyssié, J.L., Fowler, S.W., Bustamante, P., Warnau, M., 2003. Delineation of PCB uptake pathways in a benthic sea star using a radiolabelled congener. Mar. Ecol. Prog. Ser. 253, 155-163. 
Danis, B., Bustamante, P., Cotret, O., Teyssié, J.L., Fowler, S.W., Warnau, M., 2005a. Bioaccumulation of PCBs in the cuttlefish Sepia officinalis from sea water, sediment and food pathways. Environ. Pollut. 134,113-122.

Danis, B., Cotret, O., Teyssié, J.L., Bustamante, P., Fowler, S.W., Warnau, M., 2005b. Bioaccumulation of PCBs in the sea urchin Paracentrotus lividus: seawater and food exposures to a 14C-radiolabelled congener (PCB\#153). Environ. Pollut. 135, 11-16.

Dutil, J.D., Sylvestre, E.L., Gamache, L., Laroque, R., Guderley, H., 2007. Burst and coast use, swimming performance and metabolism of Atlantic cod Gadus morhua in sublethal hypoxic conditions. J. Fish Biol. 71, 363-375.

Eichinger, M., Loizeau, V., Roupsard, F., Le Guellec, A.M., Bacher, C., 2010. Modelling growth and bioaccumulation of Polychlorinated biphenyls in common sole (Solea solea). J. Sea Res. 64, 373-385.

Evans, D.O., 1990. Metabolic thermal compensation by rainbow trout: effect on standard metabolic rate and potential usable power. Trans. Am. Fish. Soc. 119, 585-600

Fleming, C.R., Billiard, S.M., Di Giulio, R.T. 2009. Hypoxia inhibits induction of aryl hydrocarbon receptor activity in topminnow hepatocarcinoma cells in an ARNTdependent manner. Comp Biochem Physiol C Toxicol Pharmacol. 150 (3), 383-389.

Fry, F.E.J., 1947. Effect of the environment on animal activity. Univ. Toronto Stud., Biol. Ser. 55, 1-62.

Fry, F.E.J., 1971. The effect of environmental factors on the physiology of fish. In: Hoar, W.S., Randall, D.J. (Eds), Environmental Relations and Behavior (VI). Academic Press, New York, pp. 1-98

Gibson, R.N., 1994. Impact of habitat quality and quantity on the recruitment of juvenile flatfishes. Neth. J. Sea Res. 32, 191-206. 
Guderley, H., Pörtner, H.O., 2010. Metabolic power budgeting and adaptative strategy in zoology: examples from scallops and fish. Can. J. Zool. 88(8), 753-763.

Hoekstra, P.F., Letcher, R. J., O’hara, T.M., Backus, S.M., Solomon, K.R., Muir C.G., 2003. Hydroxylated and methylsulfone-containing metabolites of polychlorinated biphenyls in the plasma and blubber of bowhead whales (Balaena mysticetus). Environ. Toxicol. Chem. (22) 11, 2650-2658.

Hontela, A., Rasmussen, J. B., Audet, C., Chevalier, G., 1992. Impaired cortisol stress response in fish from environments polluted by PAHs, PCBs, and mercury. Arch. Environ. Con. Tox. 22, 278-283.

Iversen, N.K., McKenzie, D.J., Malte, H., Wang, T., 2010. Reflex bradycardia does not influence oxygen consumption during hypoxia in the European eel (Anguilla anguilla). J. Comp. Physiol. B 180, 495-502.

Kelly, B.C., Gray, S.L., Ikonomou, M.G., MacDonald, J.S., Bandiera, S.M., Hrycay, E.G., 2007. Lipid reserve dynamics and magnification of persistent organic pollutants in spawning sockeye salmon (Oncorhynchus nerka) from the Fraser River, British Columbia. Environ. Sci. Technol. 41(9), 3083-3089

Jaouen-Madoulet, A., Abarnou, A., Le Guellec, A.M., Loizeau, V., Leboulender, F., 2000. Validation of an analytical procedure for polychlorinated biphenyls, coplanar polychlorinated biphenyls and polycyclic aromatic hydrocarbons in environmental samples. J. Chromatogr. A 886, 153-173.

Kannan, N., Reusch, T.B.H., Schulz-Bull, D.E., Petrick, G., Duinker, J.C. 1995. Chlorobiphenyls: Model Compounds for Metabolism in Food Chain Organisms and Their Potential Use as Ecotoxicological Stress Indicators by Application of the Metabolic Slope Concept. Environ. Sci. Technol. 29 (7), 1851-1859. 
Kraemer, L.D., Schulte, P.M., 2004. Prior PCB exposure suppresses hypoxia-induced upregulation of glycolytic enzymes in Fundulus heteroclitus. Comp. Biochem. Physiol. C 139, 23-29.

Lannig, G., Flores, J.F., Sokolova, I.M., 2006. Temperature dependent stress response in oysters, Crassostrea virginica: pollution reduces temperature tolerance in oysters. Aquat. Toxicol. 79, 278-287.

Lefrançois, C., Claireaux, G., 2003. Influence of ambient oxygenation and temperature on metabolic scope and scope for heart rate in the common sole Solea solea. Mar. EcolProg. Ser. 259, 273-284.

Lehmler H.J., Robertson, L.W., Garrison, A.W., Kodavanti, P.R.S., 2005. Effects of PCB 84 enantiomers on [3H]-phorbol ester binding in rat cerebellar granule cells and ${ }^{45} \mathrm{Ca}^{2+}-$ uptake in rat cerebellum. Toxicol. Lett. 156, 391-400.

Macgregor, K., Oliver, I.W., Harris, L., Ridgway, I.M, 2010. Persistent organic pollutants (PCB, DDT, HCH, HCB \& BDE) in eels (Anguilla anguilla) in Scotland: Current level sand temporal trends. Environ. Pollut. 158, 2402-2411.

Mallekh, R., Lagardère, J.P., 2002. Effect of temperature and dissolved oxygen concentration on the metabolic rate of the turbot and the relationship between metabolic scope and feeding demand. J. Fish Biol. 60, 1105-1115.

Mendola, P., Buck, G.M., Sever, L.E., Zielezny M., Vena J.E., 1997. Consumption of PCBcontaminated freshwater fish and shortened menstrual cycle length. Am. J. Epidemiol. $146(11), 955-960$.

Nguyen, L.P., Bradfield, C.A. 2008. The search for endogenous activators of the Aryl Hydrocarbon Receptors. Chem. Res. Toxicol. 21, 102-116.

Nie, M., Blankenship, A. L., Giesy J.P. 2001. Interactions between aryl hydrocarbon receptor (AhR) and hypoxia signaling pathways. Environ. Toxicol. Phar. 10, 17-27 
Niyogi, S., Kamunde, C.N., Wood, C.M., 2006. Food selection, growth and physiology in relation to dietary sodium chloride content in rainbow trout (Oncorhynchus mykiss) under chronic waterborne $\mathrm{Cu}$ exposure. Aquat. Toxicol. 77(2), 210-221.

Nfon, E., Cousins, I.T., Broman, D. 2008. Biomagnification of organic pollutants in benthic and pelagic marine food chains from the Baltic Sea. Sci. Total Environ. 397, 109-204.

Pörtner, H.O., Farrell, A. P., 2008. Physiology and climate change. Science 322, 690-692.

Priede, I. G., 1985. Metabolic scope in fish. In: Fish energetics: new perspectives (eds P. Tyler \& P. Calow), pp. 33-64. London, UK: Croom Helm.

Schmidt, K., Staaks G.B.O., Pflugmacher, S., Steinberg C.E.W., 2005. Impact of PCB mixture (Aroclor 1254) and TBT and a mixture of both on swimming behavior, body growth and enzymatic biotransformation activities (GST) of young carp (Cyprinus carpio). Aquat. Toxicol. 71, 49-59.

Sherwood G.D., Rasmussen, J.B., Rowan, D.J., Brodeur, J., Hontela, A., 2000. Bioenergetic costs of heavy metal exposure in yellow perch (Perca flavescens): in situ estimates with a radiotracer $\left({ }^{137} \mathrm{Cs}\right)$ technique. Can. J. Fish. Aquat. Sci. 57, 441-450.

Schurmann, H., Steffensen, J.F., 1997. Effects of temperature, hypoxia and activity on the metabolism of juvenile Atlantic cod. J. Fish Biol. 50, 1166-1180.

Sibly, R.M., Calow, P., 1989. A life-cycle theory of responses to stress. Biol. J. Linn. Soc. 37, $101-116$.

Sokolova, I. M., Lannig, G., 2008. Interactive effects of metal pollution and temperature on metabolism in aquatic ectotherms: implications of global climate change. Climate Res. 37, 181-201.

Steffensen, J.F., Bushnell, P.G., Schurmann, H., 1994. Oxygen consumption in four species of teleosts from Greenland: no evidence of metabolic cold adaptation. Polar Biol. 14, 4954. 
Underwood, A. J., (1981). Techniques of analysis of variance in experimental marine biology and ecology. Oceanogr. Mar. Biol. 19, 513-605.

van den Thillart, G., Dalla Via, J., Vitali, G., Cortesi, P., 1994. Influence of long-term hypoxia exposure on the energy metabolism of Solea solea. I. Critical $\mathrm{O}_{2}$ levels for aerobic and anaerobic metabolism. Mar. Ecol- Prog. Ser. 104, 109-117.

van Ginneken, V., Palstra, A., Leonards, P., Nieveen, M., van den Berg, H., Flik, G., Spanings, T., Niemantsverdriet, P., van den Thillart, G., Murk, A., 2009. PCBs and the energy cost of migration in the European eel (Anguilla anguilla L.). Aquat. Toxicol. 92, 213-220.

Virkki, L., Nikinmaa, M., 1993. Tributyltin inhibition of adrenergically activated sodium/proton exchange in erythrocytes of rainbow trout (Oncorhynchus mykiss). Aquat. Toxicol. 25, 139-146.

Voltura, M.B., French, J.B. Jr, 2007. Effects of Dietary PCB Exposure on Reproduction in the White-Footed Mouse (Peromyscus leucopus). Arch. Environ. Con. Tox. 52, 264-269.

Wilson, R.W., Bergman, H.L., Wood, C.M., 1994. Metabolic costs and physiological consequences of acclimation to aluminum in juvenile rainbow trout (Oncorhynchus mykiss). 2: Gill Morphology, Swimming Performance, and Aerobic Scope. Can. J. Fish Aquat. Sci. 51(3),536-544 


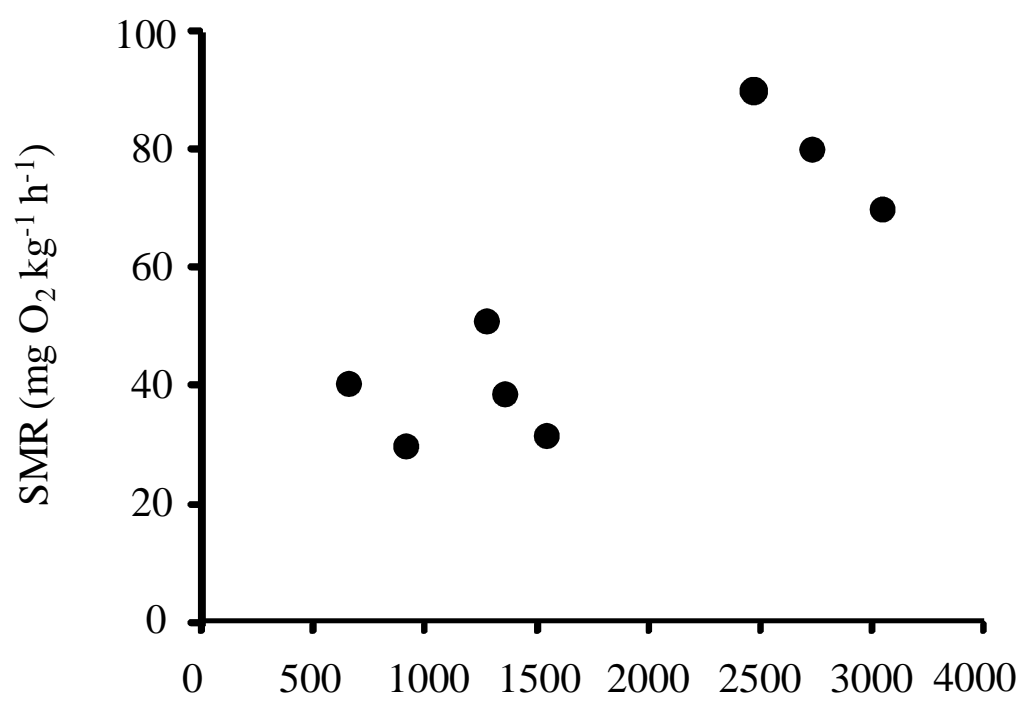

[CB 153] (ng g $\left.{ }^{-1} \mathrm{dw}\right)$

Fig.1. Correlation between the concentrations of CB $153\left(\mathrm{ng} \mathrm{g}^{-1} \mathrm{dw}\right)$ and standard metabolic rate (SMR) in the high PCB-contaminated group during 60 days (Pearson correlation: $\left.\mathrm{r}_{\mathrm{PEARSON}}=0.85, \mathrm{P}<0.001\right)$. 


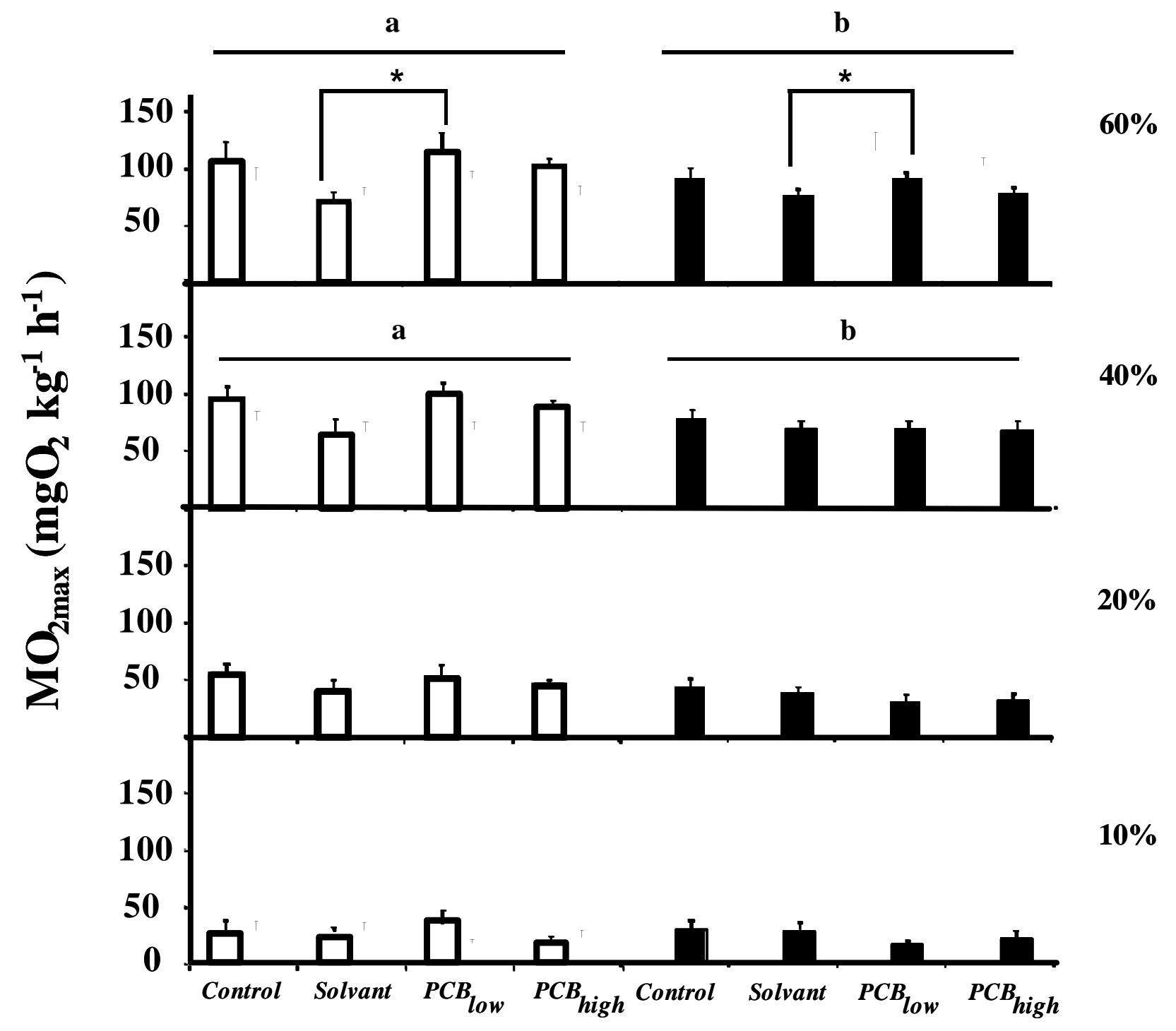

Fig.2. Average maximum metabolic rate $\left(\mathrm{MO}_{2 \max }\right)$ measured in tested groups after 30 (Control, $\mathrm{n}=8 ;$ Solvent, $\mathrm{n}=8 ; P C B_{\text {low }}, \mathrm{n}=7 ; P C B_{\text {high }}, \mathrm{n}=8$ ) and 60 days of contamination (Control, $\mathrm{n}=6$; Solvent, $\mathrm{n}=13 ; P C B_{\text {low }}, \mathrm{n}=14 ; P C B_{\text {high }}, \mathrm{n}=11$ ). Open bars: 30 days of contamination. Filled bars: 60 days of contamination. At $60 \%$ a.s., * indicates a significant difference between the treatments $(\mathrm{P}<0.05)$ independently of duration of contamination. For a given level of $\mathrm{O}_{2}$ saturation, treatments not sharing a common superscript are significantly different between 30 and 60 days of contamination $(\mathrm{P}<0.05)$. All the values are means \pm S.D. 
Table 1. Concentration ( $\mathrm{ng} \mathrm{g}^{-1} \mathrm{dw}$ ) of the four PCB congeners used for the contamination of commercial pellets. $P C B_{\text {low }}$ and $P C B_{\text {high }}$ correspond to a total concentration of 670 and 2239 ng PCB $\mathrm{g}^{-1}$ of food, respectively.

\begin{tabular}{ccc}
\hline CB composition & $P C B_{\text {low }}$ & $P C B_{\text {high }}$ \\
\hline CB 153 & 314 & 1019 \\
CB 149 & 134 & 456 \\
CB 118 & 150 & 503 \\
CB 105 & 72 & 261 \\
\hline
\end{tabular}


Table 2. Concentration (Mean $\pm \mathrm{SD}, \mathrm{ng} \mathrm{g}^{-1} \mathrm{dw}$ ) of the congener CB153 in the liver of PCBcontaminated soles after 30 and 60 days of contamination. Soles from the group $P C B_{\text {low }}$ and $P C B_{\text {high }}$ were exposed to a total of PCB concentration of 670 and $2239 \mathrm{ng}$ PCBs $\mathrm{g}^{-1}$ of food, respectively. For a given treatment $\left(P C B_{\text {low }}\right.$ or $\left.P C B_{\text {high }}\right)$, values not sharing a common superscript were significantly different $(\mathrm{P}<0.05)$

\begin{tabular}{ccc}
\hline Exposure period & $P C B_{\text {low }}$ & $P C B_{\text {high }}$ \\
\hline 30 days & $584 \pm 567^{\mathrm{a}}$ & $763 \pm 386^{\mathrm{b}}$ \\
60 days & $401 \pm 172^{\mathrm{a}}$ & $1783 \pm 934^{\mathrm{c}}$ \\
\hline
\end{tabular}


Table 3. Average ( \pm S.D.) of the Active Metabolic Rate (AMR), Standard Metabolic Rate (SMR), Aerobic Metabolic Scope (AMS) and critical oxygen saturation $\left(\mathrm{O}_{2 \text { crit }}\right)$ in the four experimental groups of sole: the PCB-exposed individuals $\left(P C B_{\text {low }}\right.$ and $\left.P C B_{\text {high }}\right)$ and the uncontaminated individuals (Control and Solvent). For each treatment, * indicates values that are significantly different between 60 and 30 days $(\mathrm{P}<0.05)$. Independently of the treatment, italics values indicate a significant effect of the exposure period (i.e. $\mathrm{O}_{2}$ crit was found to be significantly higher in the soles tested after 60 days).

\begin{tabular}{|c|c|c|c|c|c|c|c|c|}
\hline & \multicolumn{2}{|c|}{ Control } & \multicolumn{2}{|c|}{ Solvent } & \multicolumn{2}{|c|}{$P C B_{\text {low }}$} & \multicolumn{2}{|c|}{$P C B_{\text {high }}$} \\
\hline & $\begin{array}{c}30 \text { days } \\
(\mathrm{n}=8)\end{array}$ & $\begin{array}{c}60 \text { days } \\
(\mathrm{n}=6)\end{array}$ & $\begin{array}{c}30 \text { days } \\
(\mathrm{n}=8)\end{array}$ & $\begin{array}{c}60 \text { days } \\
(n=13)\end{array}$ & $\begin{array}{c}30 \text { days } \\
(\mathrm{n}=7)\end{array}$ & $\begin{array}{c}60 \text { days } \\
(n=14)\end{array}$ & $\begin{array}{c}30 \text { days } \\
(\mathrm{n}=8)\end{array}$ & $\begin{array}{l}60 \text { days } \\
(\mathrm{n}=11)\end{array}$ \\
\hline $\begin{array}{c}\text { AMR } \\
\left(\mathrm{mgO}_{2} \mathrm{~kg}^{-1} \mathrm{~h}^{-1}\right)\end{array}$ & $151.9 \pm 41.2$ & $155.8 \pm 24.7$ & $129.5 \pm 22.2$ & $143.9 \pm 43.3$ & $159.7 \pm 28.3$ & $137.1 \pm 23.5$ & $153.7 \pm 59.2$ & $173.2 \pm 73.9$ \\
\hline $\begin{array}{c}\text { SMR } \\
\left(\mathrm{mgO}_{2} \mathrm{~kg}^{-1} \mathrm{~h}^{-1}\right)\end{array}$ & $46.9 \pm 9.6$ & $45.8 \pm 18$ & $42.3 \pm 10.2$ & $53.8 \pm 12.1$ & $52.9 \pm 14.7$ & $44.3 \pm 16.5$ & $38.7 \pm 8.4$ & $52.7 \pm 18.4^{*}$ \\
\hline $\begin{array}{c}\mathrm{AMS} \\
\left(\mathrm{mgO}_{2} \mathrm{~kg}^{-1} \mathrm{~h}^{-1}\right)\end{array}$ & $105 \pm 39.6$ & $110 \pm 27.4$ & $87.2 \pm 24.8$ & $90.1 \pm 37.6$ & $106.9 \pm 21.7$ & $92.8 \pm 31.3$ & $114.9 \pm 60.7$ & $120.5 \pm 71$ \\
\hline $\mathrm{O}_{2 \text { crit (\% a.s.) }}$ & $15.5 \pm 6.4$ & $20.9 \pm 12.4$ & $22.5 \pm 2.3$ & $30.5 \pm 12.2$ & $16.5 \pm 4.3$ & $25.7 \pm 14.4$ & $16.1 \pm 5.1$ & $30.2 \pm 18.8$ \\
\hline
\end{tabular}

